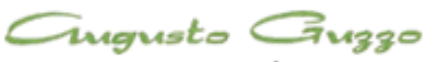

REVISTA ACADEMICA

\title{
Um olhar científico sobre a relação de intercambio do estudante brasileiro em Portugal
}

\author{
Simone Aparecida Canuto' \\ Recebido em: 15/10/2014. Aprovado em: 13/11/2014. Disponibilizado em: 26/12/2014
}

1. Simone Aparecida Canuto é Doutora em Engenharia de Produção pela Universidade Paulista (2012) com estágio doutoral na UTAD em Portugal. Mestre em Engenharia de Produção pela Universidade Paulista (2007), pós-graduada em Engenharia de Software pela Universidade São Judas Tadeu (2002) e graduada em Administração de Empresas pelas Faculdades Associadas de São Paulo (1991). Mestrando em Gestão Empresarial na Universidade de Trás-os-Montes e Alto Douro (Portugal).

\section{Resumo}

O estágio doutoral possibilita o aprimoramento dos conhecimentos científicos além de proporcionar uma vivência internacional e crescimento do pesquisador. Conhecer o destino de forma o mais abrangente possível reduz problemas de adaptação e integração dos participantes neste tipo de aperfeiçoamento acadêmico. Os programas de apoio existentes no Brasil e na maioria das Universidades do mundo têm por objetivo apoiar a diversidade e integração dos educandos. Neste texto são apresentados alguns relatos sobre as experiências desagradáveis, vividas pela pesquisadora, mas todos ocorreram fora do ambiente acadêmico. A preparação para um estágio internacional devem compreender as legislações envolvidas, as regras tanto da instituição brasileira quanto a internacional, além da cultura, língua e o clima do destino escolhido.

Palavras-chave: Portugal, doutorado, estágio internacional, intercâmbio, integração.

\begin{abstract}
The doctoral stage enables the improvement of scientific knowledge as well as providing an international experience and growth of the researcher. Know the fate of the most comprehensive possible reduces problems of adaptation and integration of the participants in this type of academic improvement. The support programs exist in Brazil and in the majority of universities in the world aims to support diversity and integration of students. In this text are some reports about the unpleasant experiences lived by the researcher, but all occurred outside the academic environment. The preparation for an international stage must understand the laws involved, the rules of both Brazilian institution for international, in addition to the culture, language and the climate of the chosen destination.
\end{abstract}

Keywords: Portugal, PhD, international internship, Exchange, integration. 


\section{Introdução}

O objetivo desta pesquisa é analisar como o fato de estudar no exterior agrega valor ao aperfeiçoamento, não apenas de outra língua, mas também de outras culturas e formas de viver e conviver de forma mais madura academicamente.

A justificativa da pesquisa e demonstrar a importancia da intensa convivencia do acadêmico com a nova cultura para apreendêla e consolidar o aprendizado demonstrando maturidade emocional e academica.

A metodologia utilizada na investigação é a pesquisa in loco, com relato de caso da propria autora em sua experiencia em Portugal.

A hipótese é de que a convivência do estudante com outro mundo social e académico proporciona a convivência intensa do estrangeiro com a população em geral, obrigando-o a adaptar ou abandonar a aventura do conhecimento.

No que tange a diversidade a convivência no mundo académico é diferente da convivência com a população em geral. Conhecer a cultura e o clima do destino é outro fator a considerar na escolha das opções de destino.

Cada universidade tem suas regras, seus apoios e seus núcleos de pesquisa, estas informações estão disponíveis em seus sites e devem ser estudadas com cautela pelos estudantes que pretendem ampliar seus conhecimentos.

A autora desconsiderou os devido cuidado na busca das informações, principalmente relacionadas ao clima e as diferenças culturais entre São Paulo e a cidade de destino - Vila Real - provocando obstáculos, enganos, aventuras e os equivocos relatados.

\section{Alguns Conceitos}

Os mestrados e doutorados podem ser definidos como pós-graduação stricto sensu, ou seja, mestrados acadêmicos e doutorados, tendo como características fundamentais a natureza acadêmica e de pesquisa e, mesmo quando voltados para setores profissionais, devem ter objetivo essencialmente científico, tendo por objetivos práticos (CAPES, 21 Maio 2014) [1]:

- formação de professores competentes que possa atender a demanda no ensino básico e superior garantindo, ao mesmo tempo, a constante melhoria da qualidade;

- estimular o desenvolvimento da pesquisa científica por meio da preparação adequada de pesquisadores;

- assegurar o treinamento eficaz de técnicos e trabalhadores intelectuais do mais alto padrão para fazer face às necessidades do desenvolvimento nacional em todos os setores.

- Estudar no exterior exige uma série de procedimentos, alguns destes serão apresentados neste capítulo e outros podem ser obtidos em sites da CAPES e do Ciência sem fronteiras.

Segundo a Portaria $\mathrm{n}^{\circ}$ 69, de 2 de maio de 2013, o doutorado sanduíche é a modalidade internacional de estudantes brasileiros regularmente matriculados em cursos de Doutorado no Brasil para realização de estágio de doutorando em universidades no exterior. Essa modalidade tem como objetivo a formação no exterior de maneira intercalada por meio da realização de um estágio supervisionado do doutorando 
por um coorientador da instituição internacional, existem formas para concorrer a bolsas de estágio pelos programas de pósgraduação no Brasil (CAPES, 2013) [2].

O pré requisito para se estudar no exterior é uma carta de aceite condicional, ou seja uma declaração da Universidade de destino, com o orientador que será responsável pela supervisão do estágio (ciências sem fronteiras, 2014) [3].

Cada universidade tem seus formulários específicos, deve verificar as regras da universidade onde está a decorrer o curso de mestrado ou doutorado e as regras de universidade destino. Outro detalhe refere-se a língua em que a documentação está escrita e as devidas traduções, caso seja uma exigência constante em uma das instituições.

\section{Vila Real, Norte de Portugal}

Para uma melhor compreensão do destino do estágio doutoral optado pela autora vale conhecer um pouco de Portugal. Como é possível verificar na Figura 1 Vila Real está na região Norte de Portugal, diferente do Brasil que está dividido em Estados, o que existe são Distritos, Municípios, Freguesias, Vilas e Aldeias (Mapa de Portugal/ cidade: Distrito de Vila Real) [4].

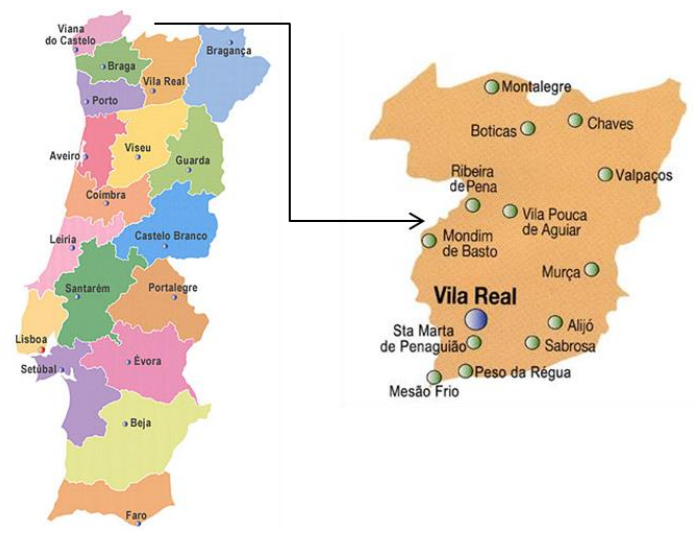

Figura 1 - Mapa de Portugal e Mapa do Distrito de Vila Real.

Fonte: Adaptada de DGPRM/DSRM/DREM [4] e

[5]

A informação sobre o clima sobre a cidade destino é que era fria, no caso podem ser observadas temperaturas abaixo de zero, algumas acentuadamente negativas, chegando a $-10^{\circ}$, e nevar. Como se pode observar nas Figuras 2 e Figura 3, fotografias tiradas pela autora em Lamas de Olo, freguesia do concelho de Vila Real, integrada no Parque Natural do Alvão, a 25 minutos da UTAD. É significativamente frio para a população de São Paulo acostumados a $+12^{\circ}$ positivos. Comparando a temperatura de Vila Real com $-10^{\circ}$, e são paulo com $+12^{\circ}$ são $22^{\circ} \mathrm{de}$ diferença.

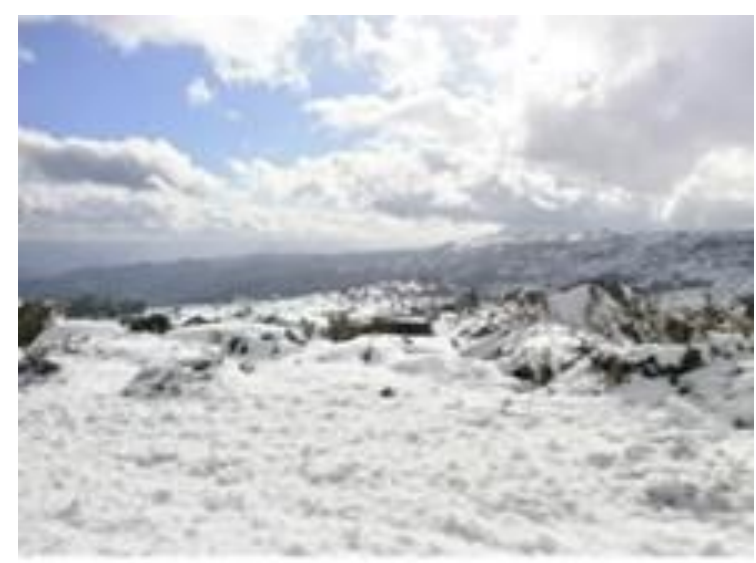

Figura 2: Foto da autora em 20/12/2013. Fonte: fotos de autoria propria dez 2013

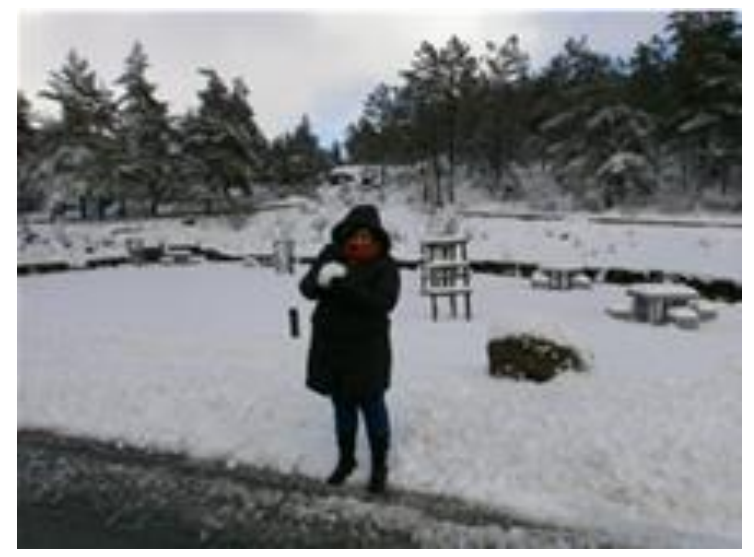

Figura 3: Foto da autora em 20/12/2013. Fonte: fotos de autoria propria dez 2013 


\section{População de Portugal}

As diferenças populacionais deveriam ser conhecidas pelos estudantes antes da viagem. Um fator importante para conhecimento do pesquisador é a composição étnica de Portugal. A região combinação ricamente vários povos: celtas, árabes, romanos, lusitanos, visigodos $\mathrm{e}$ celtiberos (demografia/populacao de portugal, 2014) [6].

O povo celtibérico - da antiga Espanha foi submetido por Cartago e em seguida pelos romanos no séc. II a.C. Eles viveram na parte ocidental da Península Ibérica. Primeiramente, como uma única tribo sediado entre os rios Doura e Tejo. Mais tarde, o nome lusitano é usado para descrever os Galaicos - povo celtibérico das montanhas a norte do Rio Douro - e por outras tribos, devido à notabilidade deste povo em lutar contra o domínio romano, mas também porque eram cultural e etnicamente muito semelhantes (LORRIO, 1999:319) [7].

Para uma melhor percepção das diferenças, a Figua 4 demonstra nos gráficos evolução da popluação de Portugal em relação ao envelhecimento populacional. Em 1960 a população portuguesa era em sua marioria consitnuída por crianças ou adolecentes, seguida por idoso e apenas 15\% eram cidadãos entre 15 e 64 anos. Já em 2011 gráfico mostra a inversão desta realidade, onde a $66 \%$ da população é composta por pessoas entre 15 e 64 anos, seguida pelos idosos e por último as crianças, o que tem deixado todos muito proeocupados com o futuro do país.

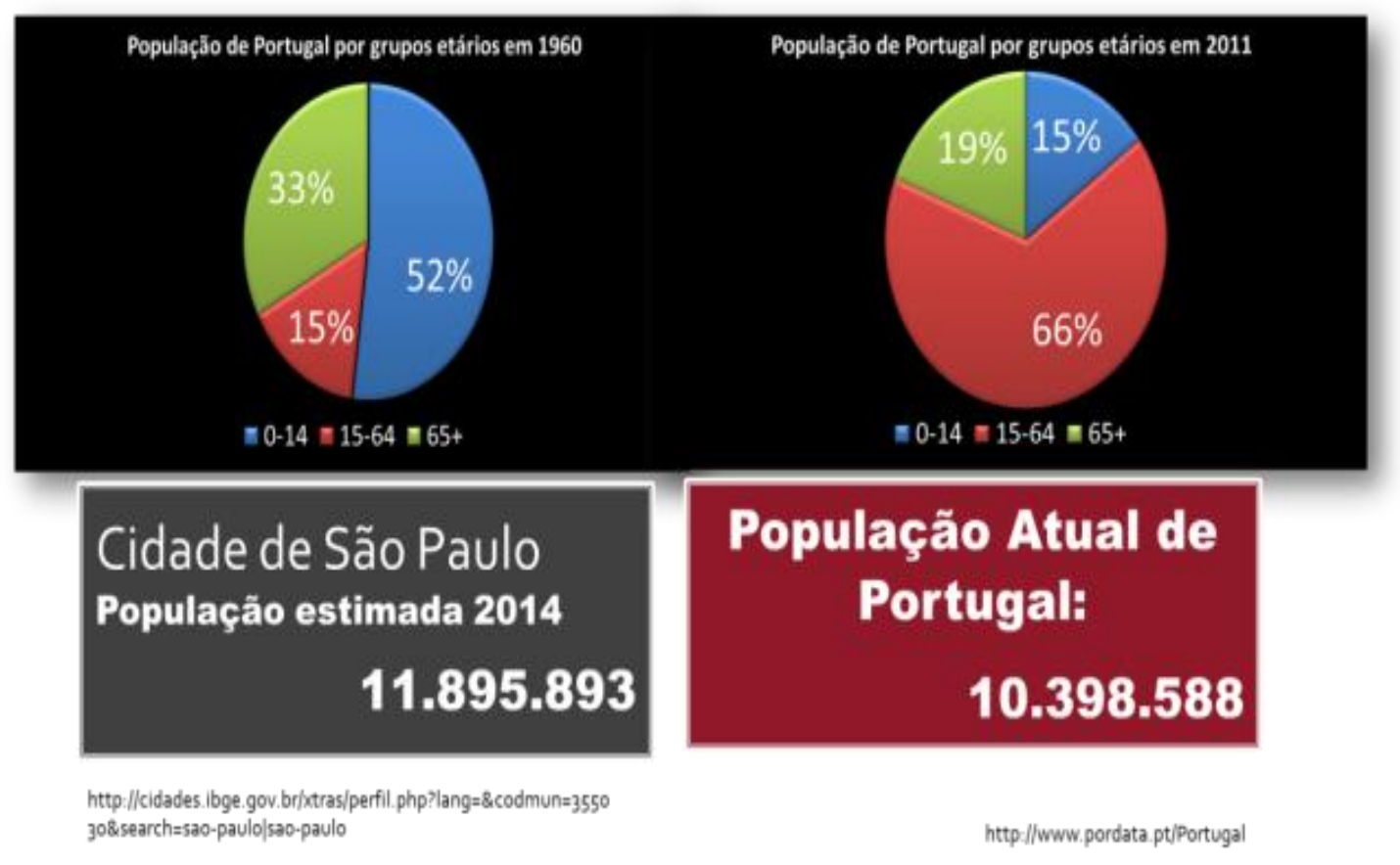

Figura 4: comparação Portugal e São Paulo. Fonte: comparação Portugal e São Paulo, IBGE, 2014.

Não é mais possível comparar as populações, do Brasil com portugal. Só na
Cidade de São Paulo há um número maior de moradores que Portugal todo. Outro ponto a 
considerar é a população paulistana que é composta por pessoas vindas de todas as partes do próprio país e do mundo. São paulo possui uma miscigenação de raças, credos e culturas, com forte tendência para as adaptações necessárias para se sobreviver em uma megalópole.

O distrito de Vila Real na região Norte de Portugal segundo o Censo de 2011 era composto por 207.184 habitantes, sendo que a cidade possui $378,8 \mathrm{Km} 2$ e população estimada de 52 mil habitantes [8].

\section{Instituto Universitário de Trás-Os- Montes e Alto Douro (UTAD).}

O Instituto Politécnico de Vila Real, criado em 1973, deu origem a Universidade de Trás-os-Montes e Alto Douro - UTAD com o estatuto criado em 1986, cujo o núcleo desta Universidade iniciou em setembro de 1979. O Estatuto da Universidade, que tem como objetivos fundamentais o Ensino, a Investigação, a Extensão e Apoio à Comunidade, deve se constituir em um Centro de Excelência para a educação permanente e para a criação, transmissão e difusão da cultura, da ciência e da tecnologia. Para tanto dispõe de diversos programas de apoio a estudantes de diversas partes do mundo de forma a apoiar a diversidade e integração dos educandos (Ciências sem fronteiras, 2014) [3].

A UTAD oferece cursos de formação ao nível de $1^{\circ}, 2^{\circ}$ e $3^{\circ}$, ou seja Licenciatura, Mestrado e Doutorado, em diversas áreas de estudo organizados. A Universidade está dividida em 5 Escolas: Escola de Ciências Agrárias e Veterinárias, Escola de Ciências Humanas e Sociais, Escola de Ciências e Tecnologia, Escola de Ciências da Vida e do Ambiente e Escola Superior de Enfermagem de Vila Real [3].

\section{Algumas das experiências vividas pela autora.}

Atualmente a autora cursa na UTAD o mestrado em gestão empresarial, tendo concluído o doutorado em 2012 em Engenharia de Produção na Universidade Paulista - UNIP. Concluiu a Pós graduação em Engenharia de Software na Universidade São Judas em 2002, em 2007 concluiu Engenharia de produção na UNIP. O bacharelado em administração nas Faculdades Associadas foi concluído em 1991

Em Março de 2010, durante um almoço com os professores na UNIP no campus da Bacelar, surgiu a ideia de fazer um estágio doutoral internacional com os professores amigos de Portugal. Após alguns contados, muitos documentos e análise da burocracia necessária surgiram uma parceria entre a Universidade de Trás-os-Montes e Alto Douro - UTAD.

Sem sucesso para a obtenção de bolsa, sendo funcionária pública na época, professora da FATEC, na unidade de São Caetano do Sul, foi possível contar com a orientação, ajuda, apoio e até orações dos amigos professores, alunos e coordenadores no afastamento para o estágio doutoral. O estágio teria início em Setembro de 2010, ou seja, deveria estar presente nas reuniões com o orientador na UTAD em Portugal.

A falta de experiência em viagem internacional foi um agravante, e dentre as várias falhas que poderiam ter sido evitadas, destaca-se a compra de passagem aérea mais barata, ou seja com escalas, atraso na saída do voo em Guarulhos, chegada com atraso em Madrid, correia no desembarque e atravessar uma aeroporto imenso após 10 horas de voo e sem dormir. Perdas da bagagem, pois o voo de Madrid ao Porto foi em uma pequena 
aeronave, com o atraso, as malas não foram transladadas gerando um transtorno de 3 dias. A fatídica experiência demonstra que a diferença do preço da passagem não compensou. Gastou-se mais nas viagens de táxi de ida e volta para o aeroporto para conseguir as malas, que decidiram enviar uma em cada voo.

A cultura e a língua diferentes, a presença do sotaque "brasileiro" chamou a atenção, associando-se às novelas, por um lado, e por outro por causa da "fama" das mulheres brasileiras. Muitas brasileiras trabalham no setor de entreterimento e sexo, o que dificulta quem busca outras atividades, como estudante com bolsa e sem trabalho por exemplo. Esta informação era de conhecimento da autora, mas por ter mais de 40 anos o peso era menor. Porém não foi preparada para tal situação.

Em 2010 ao chegar em Vila Real, Norte de Portugal, a autora residiu por 2 dias no Residencial da universidade. Lá se encontravam os estudantes sem condições de visitar os familiares nas férias, que na Europa ocorre nos meses de Julho a Setembro, denominadas férias de verão. Dentre os alunos estavam alguns de Timor Leste, Cabo Verde, entre outros países que fazem parte do programa ERASMUS - intercâmbio de estudantes. Rapidamente os estudantes se integram e interagem estabelecendo amizades. No caso em questão a autora se ligou a um grupo de Timor Leste, um país na parte oriental da ilha de Timor no sudoeste Asiático.

No início das aulas em setembro encontrou-se no ônibus com o grupo a caminho da Universidade. Ao entrar pela primeira vez estranhou a separações por gênero - na parte dianteira senhoras e senhores com mais idade. Até aí tudo certo, na sequência os profissionais das secretarias da escola, profissionais dos bancos entre outros utilizadores do transporte público. Ao fundo devidamente paramentados os alunos da UTAD, ou seja vestidos a Harry Potter, e juntinhos e apertados no lugar destinado à cadeira de rodas, todos os amigos do Timor Leste. Como boa brasileira, sozinha na cidade, fui direto conversar com eles, todos a olharam como se aquilo fosse algo reprovavel. Inclusive pelos próprios alunos do Timor.

Outro episódio peculiar aconteceu no único shopping da cidade. $\mathrm{Na}$ UTAD a autora fez amizade com uma jovem estudante de Cabo Verde, do programa ERASMOS que fazia mestrado em comunicação e trabalhava em um quiosque de café no shoping para complementar a bolsa e enviar dinheiro para a família. A autora foi ao shopping, conversou com a amiga e sentou-se em uma mesa para tomar café. Imediatamente um senhor de aproximadamente 60 anos sentouse à mesa sem pedir licença e perguntou "quanto é o convívio?"

Inicialmente sem compreender do que ele falava, ficou confusa. Após entender do que se tratava explicou que não era profissional do sexo, que era uma professora a estudar na UTAD. E teve que pedir para que ele saísse ou chamaria o segurança.

Próximo do Natal com o frio de gelar até a alma, tentando comprar casacos, no mesmo shopping se deparaou com outra dificuldade: em uma loja e foi perseguida por uma cliente, que tendo más experiências com brasileiras, ou as generalizando, foi dizer para a vendedora que no provador havia uma brasileira com (quatro) 4 peças. A perseguidora pensou que era uma moça da noite e que pretendia roubar as peças.

Foram várias aventuras, perseguições e questionamentos. Ao ser apresentada para a família do marido, todos portugueses, a sogra sempre ao apresentá-la dizia "é brasileira, mas é professora". 


\section{Discussão}

A diversidade existente no meio academico, é valorizada e insentivada. O ambiente encontrado no núcleo de mestrado e doutorado das engenharias, onde o estágio ocorreu, a integração dos alunos dos mais diversos setores de pesquisa e de vários países era total. Atuou em diversas áreas nos programas de Graduação, Mestrado e Doutorado. A universidade UTAD tem uma visão de integração dos docentes e discentes, nas salas de aulas não foi detectado nenhum tipo de preconceito, separação ou qualquer tipo de distinção.

Deve-se levar em consideração a utilização de termos próprios da região assim como a cultura e o idioma. A falta de conhecimento das expressões da região podem causar desconforto. $\mathrm{O}$ aluno deve estar preparado para assimilar a nova cultura.

A UTAD dispoe de apoio para os alunos mais carentes, mas é necessário conhecer as regras e opções disponíveis da bolsa antes de iniciar o estágio. O ideal é que se tenha recusrsos de apoio à subsistência disponíveis no Brasil. Antes da viagem deve-se equacionar os custos de moradia, alimentação e transporte, além das despesas para os deslocamentos em congressos e seminários, necessários para a consolidação científica do estudante.

Os programas de integração acadêmico e científico existem em todos os grandes centros Universitários. $\mathrm{Na}$ Europa esses congressos, seminários e encontros doutorais são uma grande oportunidade de crescimento da pesquisa e troca de informações no meio científico de mais alto nível.

Antes de iniciar um estágio internacional é importante preparar para aprender com as diferenças, aceitar as críticas e os novos desafios. O estudo em uma Universidade na Europa é diferente do oferecido no Brasil. A exigência é outra e o que se espera é que o aluno seja independete e consiga resolver seus problemas, conflitos e amplie suas competências de forma autonoma.

Existem bolsistas brasileiros que desistem ou não conseguem cumprir com os prazos e o alto nível de exigência da pesquisa. Um fator apontado pelos professores que afeta o sucesso dos alunos brasileiros é a falta da fluência no inglês. As aulas são ministradas tanto em português quanto em em inglês assim como parte do material didático. Os melhores textos e artigos científicos estão nesse idioma por ser considerado mais adequado ao mundo academico e apresentar forma mais clara de comunicação.

\section{Considerações Finais}

Todas as observaçõe consideradas relevantes e comentadas no texto sobre algum tipo de diferença ou discriminação percebida ocorreram fora do ambiente acadêmico. A melhor lição que a autora observa é que o aluno procure conhecer a região na qual irá realizar o estágio, seja doutorado, mestrado ou graduação, pois é onde irá viver e conviver por alguns anos.

Deve-se levar em consideração as diferenças culturais, a língua e os termos específicos e normas da região, pois mesmo que seja parecida não é a mesma coisa. Observar, conviver, aprender e ler sobre a região ajuda no aprendizado.

A integração depende das duas partes, é preciso aceitar as diferenças, adaptar e aceitar novos amigos, novas formas de viver e aprender, muito além do projeto de pesquisa. 


\section{Bibliografía}

[1] "Mestrados e Doutorados o que são?," CAPES, 21 Maio 2014. [Online]. Available: http://www.capes.gov.br/avaliacao/sobrea-avaliacao/mestrado-e-doutorado-o-quesao. [Acedido em 810 2014].

[2] CAPES_PDSE, Regulamento Programa de Doutorado Sanduíche no Exterior PDSE, Brasília: CAPES, 2013.

[3] Ciências_sem_Fronteiras, "Doutorado Sanduíche," cienciasemfronteiras.gov.br, [Online]. Available: http://www. cienciasemfronteiras.gov.br/web/csf/douto rado-sanduiche1. [Acedido em 910 2014].

[4] Mapas_Portugal, "Mapas de Portugal Distritos," [Online]. Available: http://www.mapas-portugal.com/Mapa_ Distritos_Portugal.htm. [Acedido em 910 2014].

[5] Mapas_Vila_Real, "Mapas de Portugal Distrito de Vila Real,” Mapas de Portugal, [Online]. Available: http://www.mapasportugal.com/Mapa_Distrito_Vila_Real_Po rtugal.htm. [Acedido em 910 2014].
[6][Online]. Available: http://www. infoescola.com/demografia/populacao-deportugal/. [Acedido em 2810 2014].

[7] Lorrio, Alberto. Los Celtíberos: análisis arqueológico de un proceso de etnogénesos. Revista de Guimarães, Volume Especial, I, Guimarães, 1999, pp. 297-319. [Online]. Available:

http://lusitania88.blogs.sapo.pt/19620.html. [Acedido em 2810 2014].

[8][Online]. Available: http://www. noticiasdevilareal.com/noticias/index.php?a ction=getDetalhe\&id=10913. [Acedido em 2810 2014].

[9] UTAD, "Instituição da Universidade de Trás-os-Montes e Alto Douro,” 2014. [Online]. Available: http://www. utad.pt/vPT/Area2/autad/instituicao/Pagin as/default.aspx. [Acedido em 810 2014].

[10] "Perguntas Frequentes sobre Educação Superior,” 2013. [Online]. Available: http://portal.mec.gov.br/index.php?option =com_content $\&$ view $=$ article $\& \mathrm{id}=14384 \& \mathrm{It}$ emid=819. [Acedido em 0102 2014]. 